\title{
Structural, opto-electronic and photoelectrochemical properties of tungsten diselenide thin films
}

\author{
D. J. Sathe $\cdot$ P. A. Chate $\cdot$ P. P. Hankare $\cdot$ \\ A. H. Manikshete $\cdot$ U. B. Sankpal $\cdot$ V. M. Bhuse
}

Received: 6 October 2014/Accepted: 2 December 2014/Published online: 21 March 2015

(C) The Author(s) 2015. This article is published with open access at Springerlink.com

\begin{abstract}
Nanocrystalline tungsten diselenide thin films have been deposited on non-conducting glass and stainless steel substrates by chemical methods. Various preparative conditions were optimized for the formation of thin films. The X-ray diffraction analysis shows that the film samples are in layer-hexagonal crystal structure. EDAX analysis shows that the films are nearly stoichiometries of W:Se. Optical properties show a direct band gap nature with band gap energy $1.5 \mathrm{eV}$. Specific electrical conductivity was found to be in the order of $10^{-3}$ to $10^{-2}(\Omega \mathrm{cm})^{-1}$. The photoelectrochemical characterization of the films was carried out by studying current-voltage characteristics, capacitance-voltage and power output characteristics. The
\end{abstract}

\section{J. Sathe}

Department of Chemistry, KIT's College of Engineering,

Kolhapur, Maharashtra, India

e-mail: djsathe07@yahoo.co.uk

P. A. Chate $(\bowtie)$

Department of Chemistry, JSM College, Alibag-Raigad,

Maharashtra, India

e-mail: pachate04@rediffmail.com

P. P. Hankare

Department of Chemistry, Shivaji University, Kolhapur,

Maharashtra, India

A. H. Manikshete

Department of Chemistry, Walchand College, Solapur,

Maharashtra, India

U. B. Sankpal

Department of Chemistry, R.P. Gogate- R.V. Jogalekar College

of Arts Science and Commerce, Ratnagiri, Maharashtra, India

V. M. Bhuse

Department of Chemistry, Rajaram College, Kolhapur,

Maharashtra, India efficiency of photoelectrode was found to be $1.31 \%$ using iodine-poly iodide electrolyte.

Keywords Nanostructure - EDAX - Chemical synthesis . Electrical properties $\cdot$ Efficiency $\cdot$ Fill factor

\section{Introduction}

Group VI transition metal dichalcogenides $\left(\mathrm{MX}_{2}\right.$; $\mathrm{M}=\mathrm{Mo}, \mathrm{W}$ and $\mathrm{X}=\mathrm{S}$, Se and Te) constitute structurally and chemically well-defined compounds within the family of materials. It belongs to the family of layer-type structure compounds (Wisser and Landa 1973; Whittingham and Levy 1979). Currently, one of the best materials for tailoring of band gaps is from the VI group of transition metal dichalcogenides (Deshpande et al. 2011). Tungsten diselenide belongs to a class of transition metal dichalcogenides compound with layered structure in which atoms forming each layer are covalently bound, while adjacent layers are taken by weak Van der Waals forces. It delivers several applications for low-cost photovoltaic cells, solid lubricants, etc. (Abruna et al. 1982; Kautek et al. 1982; Kline et al. 1980; Voevodin et al. 1999; Beato et al. 2006). There are a number of methods employed for the synthesis of $\mathrm{WSe}_{2}$ thin film, such as chemical vapor deposition, electrodeposition, spray pyrolysis, physical vapor deposition and chemical method (Gawale et al. 2010; Delphine et al. 2003; Devadasan et al. 2003; Deshpande et al. 2012; Yang et al. 2008; Hankare et al. 2009a; Delphine et al. 2011). But chemical bath deposition method is an alternative, low-cost method which can operate at low processing temperature and provides large-area deposition. Therefore, it was thought to be of interest to synthesize the nanocrystalline tungsten diselenide thin film by a chemical 
route at room temperature using citric acid as a complexing agent. The film was studied for structural, compositional, optical, electrical and photoelectrochemical performance.

\section{Experimental details}

The substrates used for depositing the films were nonconducting glass slides of the size $75 \times 25 \times 2 \mathrm{~mm}$ (Blue Star Co., Mumbai) and good quality polished stainless steel strips. The films deposited on the glass substrates were used for characterization of the films, whereas the films deposited on stainless steel were used for photoelectrochemical study.

All the chemicals used were of analytical grade. Sodium tungstate, citric acid, hydrazine hydrate, anhydrous sodium sulfite and selenium powder were obtained from S.D. Fine Ltd., India. All the solutions were prepared in double distilled water. Sodium selenosulfate was prepared by following the method reported earlier (Hankare et al. 2010).

The deposition of tungsten diselenide thin films was made in a reactive bath. The solution was obtained by mixing $15 \mathrm{~mL}(0.25 \mathrm{M})$ sodium tungstate, $7 \mathrm{~mL}(1 \mathrm{M})$ citric acid, $10 \mathrm{~mL}(10 \%)$ hydrazine hydrate and $10 \mathrm{~mL}$ ammonia solution in a beaker. To this, $30 \mathrm{ml}(0.25 \mathrm{M})$ sodium selenosulfate was added and the total volume of the reaction mixture was made to $100 \mathrm{ml}$ by adding double distilled water. The temperature of the bath was maintained at $278 \mathrm{~K}$ using an ice bath. Individual solutions were cooled to $278 \mathrm{~K}$ and mixed to avoid precipitation. The solution was stirred vigorously before dipping stainless steel as well as glass substrates, which were kept vertically slightly tilted in the reactive bath. The temperature of the bath was then allowed to increase up to $298 \mathrm{~K}$ very slowly. After $3 \mathrm{~h}$, the slides were removed and washed several times with double-distilled water. The deposited substrate was dried naturally, preserved in dark desiccators over anhydrous $\mathrm{CaCl}_{2}$ and subjected to various characterizations. The thickness of tungsten diselenide thin film was measured by the weight difference method and found to be $0.4 \mu \mathrm{m}$.

\section{Results and discussion}

Structural characterization

Crystallographic studies of tungsten diselenide thin film were characterized by using a Phillips PW-1710 X-ray diffractometer in the $2 \theta$ range from $10^{\circ}$ to $80^{\circ}$. The XRD pattern of $\mathrm{WSe}_{2}$ thin film is shown in Fig. 1. The XRD pattern shows a hump between $14^{\circ}$ and $36^{\circ}$ due to the amorphous glass substrate. The presence of a large number

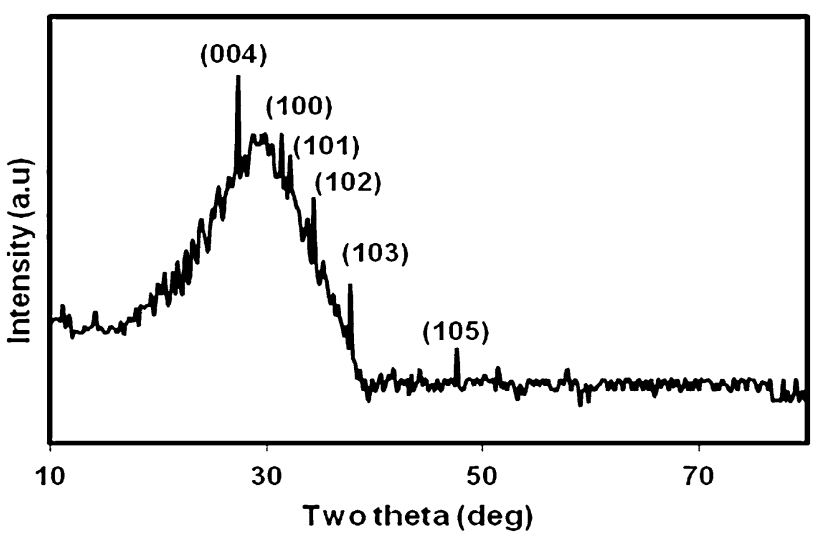

Fig. 1 XRD pattern of tungsten diselenide thin film

of peaks indicates that the films are polycrystalline in nature. The observed ' $d$ ' values of depositing samples were in full accord with the standard ' $d$ ' values taken from JCPDS diffraction file No. 06-0080. Comparison of observed ' $d$ ' with standard ' $d$ ' values confirms that chemically deposited film shows a single-phase compound with typical lines belonging to the hexagonal structure in accordance with the literature-reported data (Gawale et al. 2010; Delphine et al. 2003; Devadasan et al. 2003; Hankare et al. 2009a, 2010; Gayathri et al. 2012; Sathe et al. 2010).

$\mathrm{WSe}_{2}$ showed prominent peaks due to reflections from (004), (100), (101), (103) and (108) planes of a hexagonal $\mathrm{WSe}_{2}$ structure. The lattice parameters of the hexagonal phase were calculated using the relation:

$\frac{1}{d^{2}}=\frac{4}{3} \frac{\left(h^{2}+h k+k^{2}\right)}{a^{2}}+\frac{l^{2}}{c^{2}}$.

The lattice parameters ' $a$ and $c$ ' of $\mathrm{WSe}_{2}$ film was found to be $a=3.325$ and $c=12.921 \AA$, respectively. These values are in good agreement with the earlier reported value (Hankare et al. 2009a, 2010; Gayathri et al. 2012; Sathe et al. 2010). The average crystallite size was calculated using Scherrer formula:

$D=\frac{K \lambda}{\beta \cos \theta}$,

where $D$ is the crystallite size $(\AA), \lambda$ is the X-ray wavelength $(\AA), \beta$ is the full width at half maximum $(\mathrm{rad}), \theta$ is the Braggs diffraction angle and $k$ is constant (0.94) (Patterson 1939; Cuility 1959; West 1987). The average crystallite size was calculated by resolving the highest intensity peak, i.e., (004) plane. The average crystallite size of the tungsten selenide thin film was found to be $34 \mathrm{~nm}$. The microstrain ( $\varepsilon$ ) developed in the films was calculated using an equation:

$\varepsilon=\beta \cos \theta / 4$.

The value was found to be $2.418 \times 10^{-4}$. 


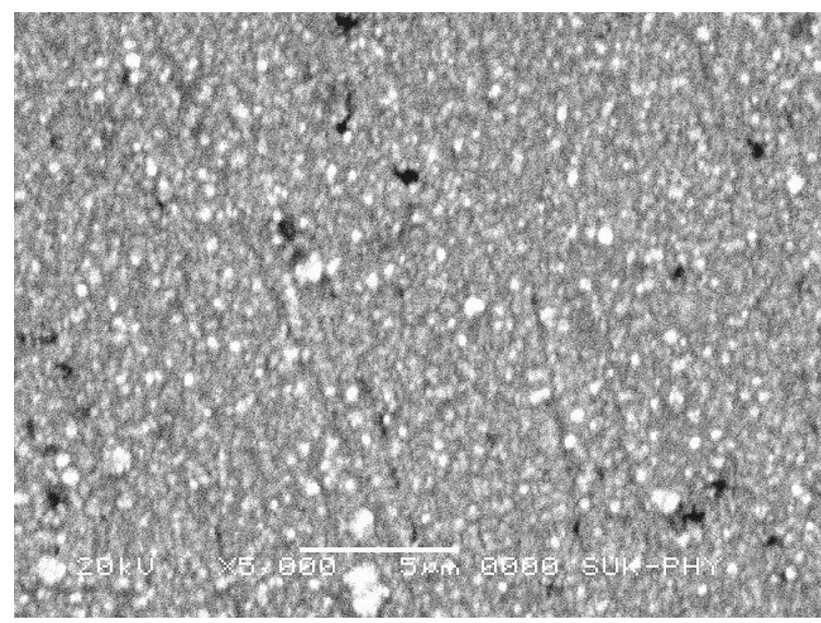

Fig. 2 Scanning Electron Micrographs for $\mathrm{WSe}_{2}$ thin film

Surface morphology

The surface morphology of tungsten diselenide thin film was also studied by scanning electron microscopy (SEM). The SEM micrograph of $\mathrm{WSe}_{2}$ thin film is presented in Fig. 2. $\mathrm{WSe}_{2}$ thin film is homogenous and well covers the glass substrate. The spherical grains are seen to be blended with the adjacent ones. This type of morphology is typical of layered structure. The average grain size was calculated using Contrell's method. This method relates the number of intercepts of grain boundary per unit length ' $\mathrm{P}_{L}$ ' and is given by;

$\mathrm{P}_{L}=(n / 2 \pi r) M$,

where $n$ is the total number of intercepts, $r$ the radius of curvature and $M$ the magnification used. Using $\mathrm{P}_{L}$, the grain size ' $L$ ' was determined by using the following relation;

$L=\left[1 /\left(\mathrm{P}_{L}\right) 1 / 2\right]$.

The mean grain size as calculated from SEM was found to be in accord with those obtained from Scherrer's formula in XRD.

\section{Compositional studies}

Figure 3 shows the EDAX patterns for the typical $\mathrm{WSe}_{2}$ thin film sample. The stoichiometry of the grown crystals was analyzed by EDAX and it was found that the growth crystals possess nearly perfect stoichiometry with the chemical formula $\mathrm{WSe}_{2}$. No impurities were present in the limit of sensitivity. Wt\% of tungsten and selenium was found to be 55.12 and 44.88 , respectively.

\section{Optical characterization}

The optical absorption spectrum of the film was recorded with UV-VIS-NIR Spectrophotometer; Hitachi-330

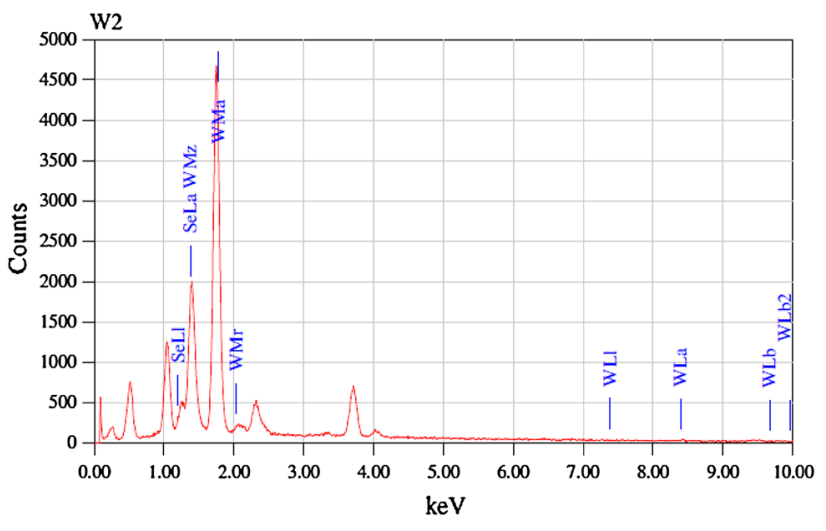

Fig. 3 EDAX of the $\mathrm{WSe}_{2}$ thin film

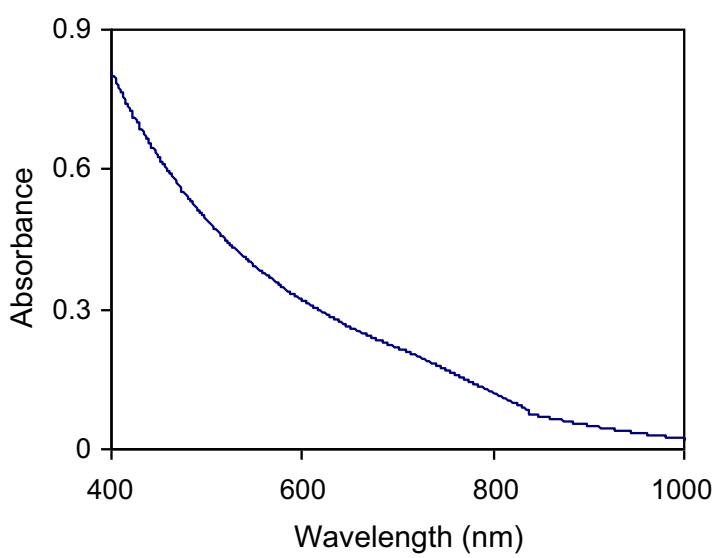

Fig. 4 Absorption spectrum of tungsten diselenide thin film

(Japan). The optical absorption spectrum of tungsten diselenide film was analyzed in the wavelength of $400-1,000 \mathrm{~nm}$. Figure 4 shows the variation of optical absorption with wavelength. The study demonstrates the presence of absorption edge of exponential shape It is due to the homogeneity of films and normal band structure. The spectra show two regions, one for higher wavelength with practically lower absorption and the other for lower wavelength in which absorption increases steeply. Based on the observed optical absorbance, $(\alpha \mathrm{h} v)^{2}$ is plotted as a function of photon energy (hv) and shown in Fig. 5. The simplest form of the equation obeyed near and above the absorption edge is (Hankare et al. 2009).

$\alpha \mathrm{h} v=A\left(\mathrm{~h} v-E_{\mathrm{g}}\right)^{n}$,

where $\alpha$ is the absorption coefficient $\left(\mathrm{cm}^{-1}\right), \mathrm{h} v$ is the photon energy (eV) and $A$ and $n$ are constants. $A$ is a complex parameter, which depends on temperature, photon phonon energies, etc. The $n$ values are $0.5,1.5,2$ and 3 for allowed direct, forbidden direct, allowed indirect and forbidden indirect transition, respectively. A plot of $(\alpha \mathrm{h} v)^{2}$ versus $h v$ should be a straight line whose intercept to the 


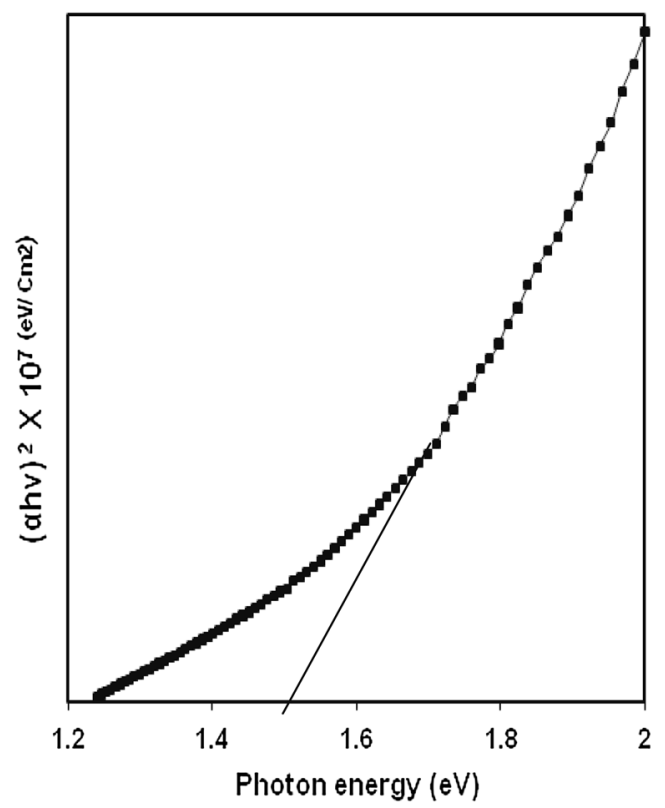

Fig. 5 Plot of $(\alpha h v)^{2}$ with respect to photon energy

$\mathrm{x}$-axis gives the optical band gap. The band gap value of the tungsten diselenide was found to be $1.5 \mathrm{eV}$.

\section{Electrical properties}

The electrical conductivity measurement was carried out in the temperature range $300-525 \mathrm{~K}$ on a Zintek $502 \mathrm{BC}$ milliohmmeter using a two-probe method. At room temperature, the specific conductance was found to be in the order of $10^{-3}$ to $10^{-2}(\Omega \mathrm{cm})^{-1}$, which agrees well with the earlier reported value (Hankare et al. 2009a; Sathe et al. 2010). It is observed that the conductivity of the film increases with increase in temperature. This indicates the semiconducting behavior of the thin film. The electrical transport properties play a key part in deciding the character as well as applications of the semiconductor devices. These properties are mainly influenced by their structural characteristics, purity, nature and the concentration of the impurities (Chopra 1969; Harbeke 1985; Rusu et al. 2003). A plot of $\log$ (conductivity) versus inverse temperature $(1,000 / \mathrm{T})$ is indicated in Fig. 6. There are two distinct linear regions, suggesting the presence of two-conduction mechanism, the low-temperature intrinsic and high-temperature extrinsic. In the lower temperature range $(300-375 \mathrm{~K})$ is characterized by a small slope. In the higher temperature range, the curve is characterized by a large slope. The activation energy is counted using the Arrhenius equation. The activation energy obtained from the linear portion of a graph is found to be 0.032 and $0.438 \mathrm{eV}$ for the low-temperature and high-temperature region respectively.

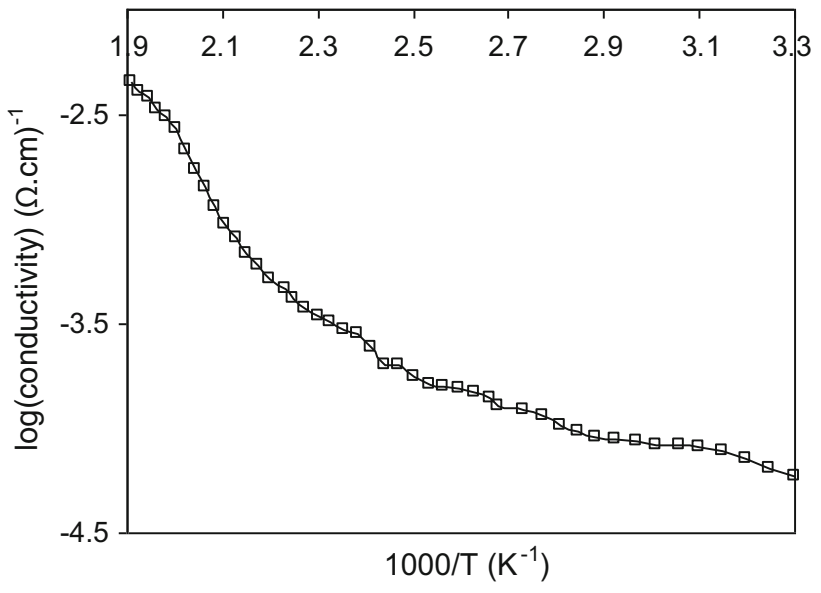

Fig. 6 The variations of $\log$ (conductivity) with inverse temperature

Photoelectrochemical performance

A PEC cell with configuration $n-W_{2} \mid \mathrm{NaI}(2 \mathrm{M})+\mathrm{I}_{2}$ (1 M) I C (graphite) was organized. A schematic diagram of the photoelectrochemical solar cell is shown in Fig. 7. Even in the dark, photoelectrochemical cells show dark voltage and dark current. The polarity of this dark voltage is negative toward the semiconductor electrode. The sign of the photovoltage gives the conductivity type of tungsten diselenide. This suggests that tungsten diselenide is an n-type semiconductor.

Current-voltage (I-V) characteristics of photoelectrochemical cell in the dark have been studied at $303 \mathrm{~K}$ and shown in Fig. 8. The characteristics are non- symmetrical indicating the formation of the rectifying type of junction (Deshmukh and Holikatti 1994). The Butler-Volmer relation can be applied to the tungsten diselenide electrolyte interface and the observed magnitude of the symmetry factor shows rectifying Schottky type of junction. The measurements of capacitance as a function of applied voltage provided useful information such as the type of conductivity, depletion layer width and flat band potential. Flat band potential can be obtained using the Mott-Schottky relation by standardizing with saturated calomel electrode (SCE):

$C^{-2}=[2 / q \varepsilon \varepsilon 0 N d]\left(V-V_{\mathrm{fb}-\mathrm{k}} T / q\right)$,

where symbols have their usual meaning. The variation of $C^{-2}$ in voltage for representative samples is shown in Fig. 9. Intercepts of plots on the voltage axis determine the flat band potential value of the junction. The flat band potential value was found to be $-0.447 \mathrm{~V}$ (SCE) for $\mathrm{WSe}_{2}$ thin film using iodine/iodide redox electrolyte. The nonlinear nature of the graph is an indication of graded junction formation between tungsten diselenide and iodine-iodide electrolyte. Non-planar interface, surface 
Fig. 7 Schematic diagram of photoelectrochemical solar
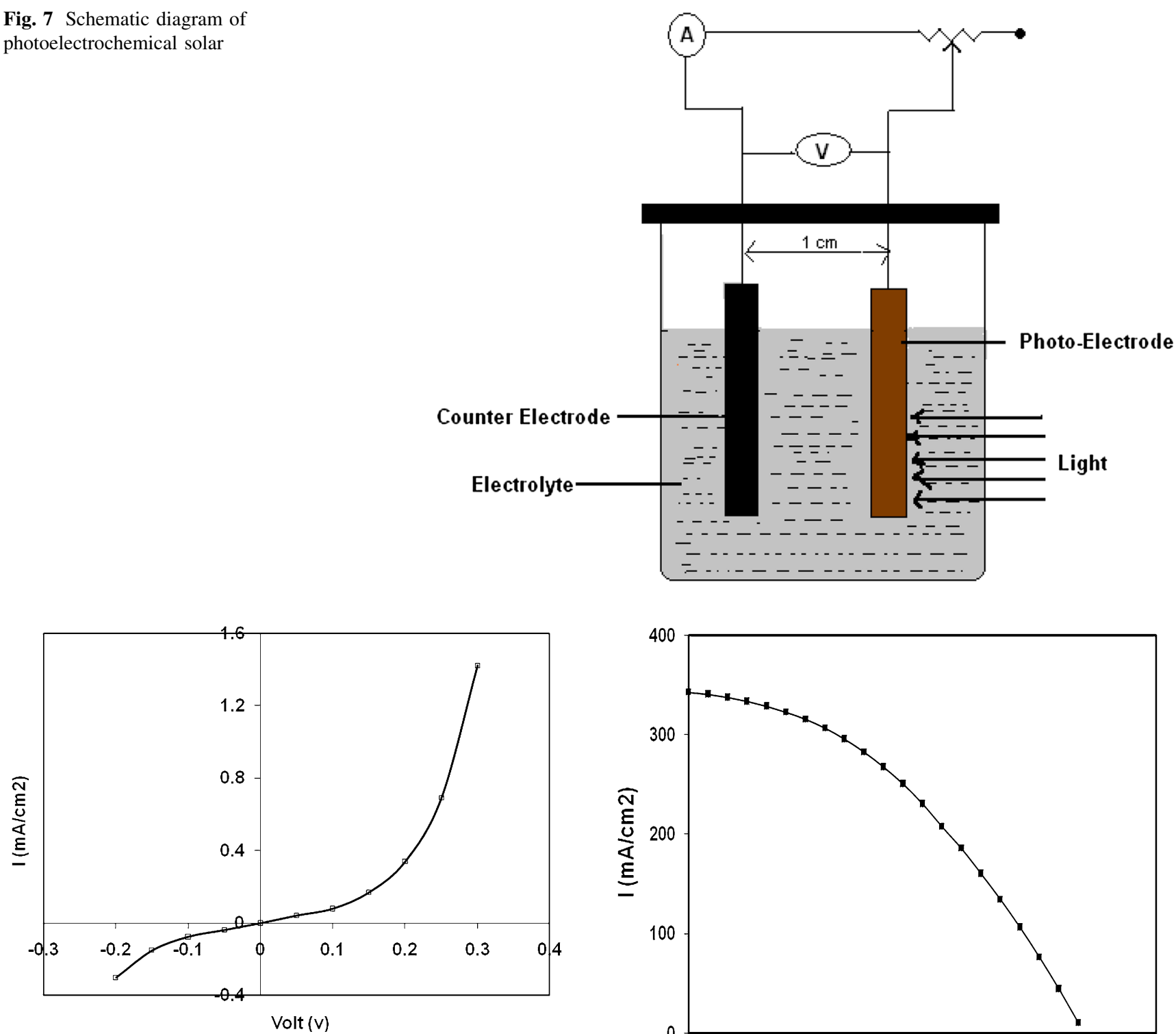

Fig. 8 I-V characteristics of tungsten diselenide photoelectrode

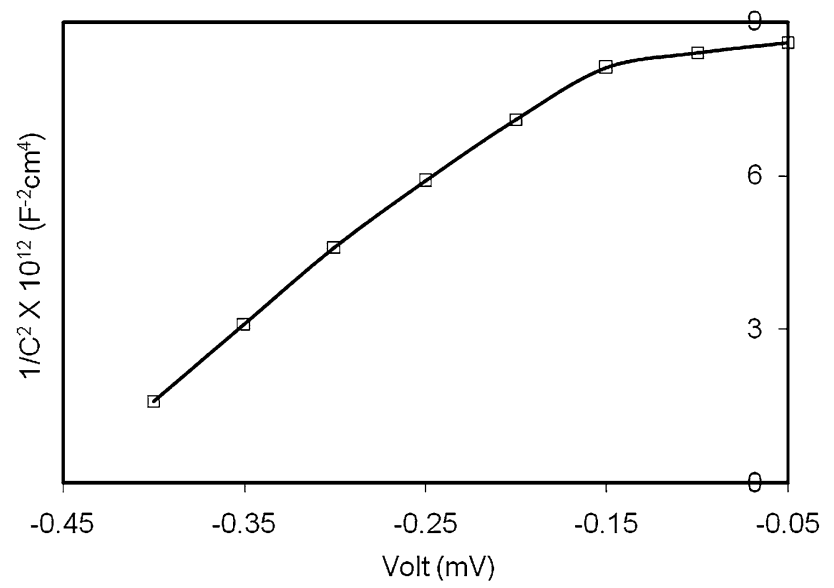

Fig. 9 C-V characteristics of tungsten diselenide photoelectrode

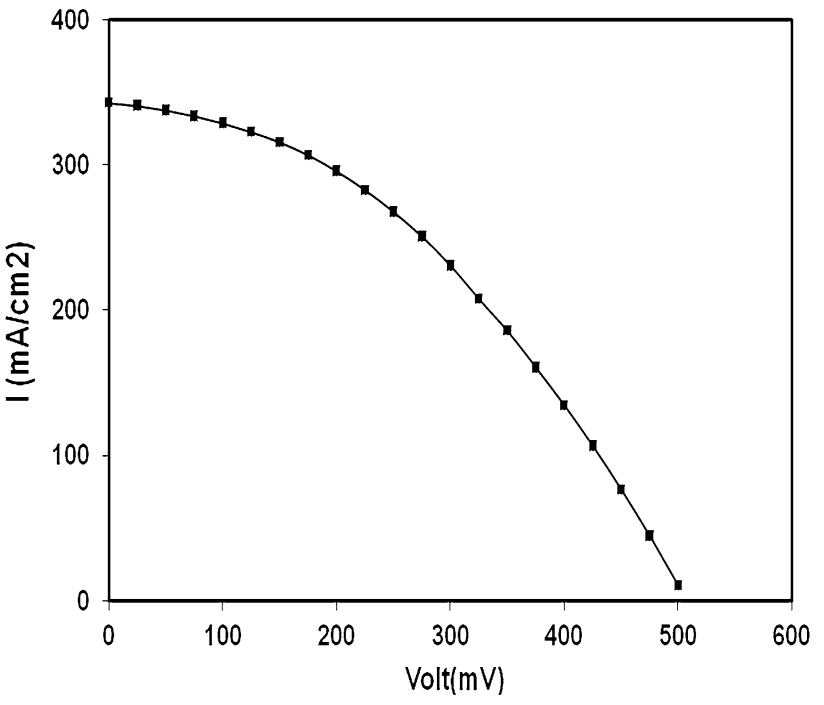

Fig. 10 Power output curves for tungsten diselenide photoelectrode

roughness and ionic adsorption on the photoelectrode surface may be possible reasons for deviation from linearity in the $\mathrm{C}-\mathrm{V}$ plot (Hankare et al. 2008). Figure 10 shows the photovoltaic power output characteristics of a cell under illumination of $30 \mathrm{~mW} / \mathrm{cm}^{2}$. The maximum power output of the cell is given by the largest rectangle that can be drawn inside the curve. The open circuit voltage and short circuit current are found to be $493 \mathrm{mV}$ and $339 \mu \mathrm{A}$, respectively. The calculation shows that the fill factor is $38.19 \%$. The power conversion efficiency is found to be $1.31 \%$. The series resistance and shunt resistance were calculated from the slope of the power output characteristics using the relation: 
$(\mathrm{d} I / \mathrm{d} V)_{I=0}=\left(1 / R_{\mathrm{s}}\right)$,

$(\mathrm{d} I / \mathrm{d} V)_{v=0}=\left(1 / R_{\mathrm{sh}}\right)$.

The values of $R_{\mathrm{s}}$ and $R_{\mathrm{sh}}$ were found to be 828 and $429 \Omega$, respectively.

\section{Conclusions}

(1) It is possible to deposit tungsten diselenide thin films on stainless steel as easily as glass substrates at room temperature.

(2) The deposited tungsten diselenide thin films are nearly stoichiometries, with crystalline nature, hexagonal structure and band gap of $1.5 \mathrm{eV}$.

(3) The material shows promising photo-response when tested in iodine-iodide electrolyte.

Acknowledgments Authors are thankful to SERB-DST, New Delhi for the financial support under the project No. SB/FT/CS-018/2013.

Open Access This article is distributed under the terms of the Creative Commons Attribution License which permits any use, distribution, and reproduction in any medium, provided the original author(s) and the source are credited.

\section{References}

Abruna HD, Hope GA, Bard AJ (1982) J. Electro chem Soc 129:2224

Beato P, Blume A, Girgsdies F, Jentoft R, Schoegl R, Timpe O, Trunsche A, Weinberg G, Basher Q, Hamid F, Hamid S, Oma E, Mohod S (2006) Appl Catal A 307:137

Chopra K (1969) Thin film phenomenon. McGraw-Hill, New York

Cuility BD (1959) Elements of X-ray diffraction. Addison Wesley, New York
Delphine SM, Jayachandran M, Sanjeeviraja C (2003) Mat Chem Phys $81: 78$

Delphine SM, Jayachandran M, Sanjeeviraja C, Almusallam AW (2011) Int J Chem Tech Res 3(2):846-852

Deshmukh LP, Holikatti SS (1994) J Phys D Appl Phys 27:1786

Deshpande MP, Parmar MN, Pandya NN, Bhatt SV, Chaki SH (2011) Ame J Mat Sci 1(2):149-153

Deshpande MP, Parmar MN, Pandya NN, Chaki S, Bhatt SV (2012) Phys B 407:808-812

Devadasan J, Sanjeeviraja C, Jayachandran M (2003) Mat Chem Phys 77:397

Gawale SN, Mane RM, Sargar AM, Mane SR, Kharade RR, Bhosale PN (2010) Arc Appl Sci Res 2(1):218-224

Gayathri S, Muthumati S, Shymala A, Devi G, Vijayalakshimi R, Sanjeeviraja C (2012) J Appl Sci 12(16):1706-1709

Hankare PP, Chate PA, Chavan PA, Sathe DJ (2008) J Alloys Compd 461:623

Hankare PP, Manikshete AH, Sathe DJ, Chate PA, Rathod KC (2009a) Mat Chem Phy 113:183

Hankare PP, Manikshete AH, Sathe DJ, Chate PA, Patil AA, Garadkar KM (2009b) J Cry Growth 311:3386

Hankare PP, Manikshete AH, Sathe DJ, Chate PA (2010) J Mater Sci Mater Electron 21:698-701

Harbeke G (1985) Polycrystalline semiconductors: physical properties and applications. Springer, Berlin

Kautek W, Gerischer H, Tributsch H (1982) J Electrochem Soc 127:2471

Kline G, Kam KK, Canfield D, Parkinson BA (1980) Sol Ene Mater $4: 2471$

Patterson AL (1939) Phys Rev 56:978

Rusu G, Popa M, Salaoru I (2003) Appl Surf Sci 218:222

Sathe DJ, Hankare PP, Manikshete AH, Chate PA, Patil AA (2010) J Alloy Com 499:187

Voevodin A, Neull J, Zabinski J (1999) Surf Coat Technol 36:116

West AR (1987) Solid state chemistry \& its applications. Wiley, Singapore

Whittingham MH, Levy F (1979) Intercalated layered materials, Reidel Dordrecht, p 533

Wisser O, Landa S (1973) Catalysts, their properties and application. Oxford, Pergamon

Yang J, Yao H, Liu Y, Zhang Y (2008) Nanoscale Res Lett 3:481-485 